\title{
Níveis de carnitina na ração no desempenho corporal de tricogáster léri (Trichogaster leeri bleeker, 1852)
}

\author{
[Carnitine levels in feed of body performance of the gouramis (Trichogaster leeri bleeker, 1852)] \\ W.C.T.Tonini ${ }^{1}$, P.P.Mendonça ${ }^{1}$, M.F.Polese ${ }^{1}$, M.L.C. Abreu ${ }^{1}$, \\ D.C. Matos ${ }^{1}$, M.V. Vidal Jr. ${ }^{2}$, D.R.Andrade ${ }^{2}$ \\ ${ }^{1}$ Pós-graduação - LZNA_CCTA/UENF - Campos dos Goytacazes, RJ \\ ${ }^{2}$ LZNA-CCTA/UENF - Campos dos Goytacazes, RJ \\ RESUMO
}

\begin{abstract}
Foram avaliados os efeitos de carnitina na dieta de Trichogaster leeri, com peso inicial de 0,5 $\pm 0,2 \mathrm{~g}$, distribuídos aleatoriamente e individualmente em aquários plásticos $(1000 \mathrm{~mL})$, com renovação total da água a cada 48 horas. Cinco dietas isocalóricas, contendo $28 \%$ de proteína bruta e $3100 \mathrm{kcal}$ de energia bruta, foram elaboradas com a suplementação de T1 $=0 \mathrm{mg}$, T2 $=300 \mathrm{mg}$, T3 $=600 \mathrm{mg}$, T4 = 900mg e T5 $=1200 \mathrm{mg}$ de 1 -carnitina $/ \mathrm{kg}$ de ração. As dietas foram administradas três vezes ao dia, ad libitum, durante 45 dias. Foram avaliados comprimento total e padrão, altura, peso final e tamanho de cauda, além do ganho de peso, conversão alimentar e fator de condição. Em todas as características analisadas, o tratamento de $900 \mathrm{mg}$ de carnitina/kg foi o mais eficiente no desempenho zootécnico para o T. leeri, e, após cálculos dos pontos máximos, sugere-se a concentração de $1.000 \mathrm{mg} / \mathrm{kg}$ de ração. Observou-se diferença significativa para tamanho de cauda, altura do corpo, peso final e fator de condição.
\end{abstract}

Palavras-chave: peixe, suplementação, nutrição, ornamental

\begin{abstract}
The effects of carnitine were evaluated in diets fed to Trichogaster leeri, initial weight $0.5 \pm 0.2 \mathrm{~g}$ and individually randomized into plastic containers $(1000 \mathrm{~mL})$, with total renewal of water every 48 hours. Five isocaloric diets containing $28 \%$ crude protein and 3100 kcalof gross energy were made with the supplementation of: $\mathrm{T1}=0 \mathrm{mg} ; \mathrm{T2}=300 \mathrm{mg} ; \mathrm{T3}=600 \mathrm{mg} ; \mathrm{T4}=900 \mathrm{mg} ;$ and T5=1200mg of l-carnitina $/ \mathrm{kg}$ feed. The diets were administered three times daily ad libitum for 45 days. Total and standard length, height, weight and size of the tail end, in addition to weight gain, feed conversion ratio and condition factor were evaluated. In all parameters examined the treatment of $900 \mathrm{mg}$ of carnitine/kg was the most efficient on the performance for the T. leeri, and after calculating the maximum points, a concentration of $1.000 \mathrm{mg} / \mathrm{kg}$ feed is suggested. There was significant difference in tail length, body height, final weight and condition factors.
\end{abstract}

Keywords: fish, supplementation, nutrition, ornamental

\section{INTRODUÇÃO}

A produção de peixes ornamentais é uma modalidade da aquicultura em plena expansão nas últimas décadas, chegando a comercializar mundialmente cerca de 300 milhões de dólares somente com peixes de águas continentais. Mesmo que $60 \%$ deste total sejam oriundos de países em desenvolvimento, o Brasil ainda está iniciando sua inserção neste mercado, contribuindo com apenas $1-2 \%$ do consumo mundial (Livengood e Chapman, 2007), tendo exportado, de 2005 a 2008, em torno de 30 milhões de exemplares, gerando mais de 5 milhões de dólares em divisas (Diagnóstico..., 2008).

Recebido em 13 de maio de 2011

Aceito em 2 de agosto de 2011

E-mail: mvidal@uenf.br 
O Trichogaster leeri, assim como as demais espécies de tricogásteres, pertence à Subordem Anabantoidei; é conhecido no Brasil como tricogáster ou léri e internacionalmente como Gourami. Esses peixes são caracterizados principalmente pela presença do órgão de respiração aérea acessória (órgão labirintiforme), localizado próximo à cavidade branquial. Os gouramis também são conhecidos como labirintídeos, nome derivado do órgão de respiração. Eles são originalmente encontrados do oeste da África até o leste da Ásia e atualmente podem ser encontrados sendo produzidos em inúmeros países e apresentando elevado potencial econômico (Zuanon et al., 2004). O Trichogaster leeri é considerado carnívoro, com a dieta natural composta por diferentes espécies de invertebrados (Degani, 1990). É encontrado em águas cuja condutividade elétrica varia de 22 a $718 \mathrm{mS}$, dureza total de 1,3 a $185 \mathrm{mg} / \mathrm{L} \mathrm{CaCO} 3$ e valores de $\mathrm{pH}$ de 5,8 a 7,4 (Geisler et al., 1979, citados por Cole et al., 1999), sendo, portanto, altamente adaptável a diferentes condições ambientais.

O T. leeri é uma boa espécie para servir como modelo para estudos biológicos pelas características que apresenta como gerador de prole numerosa e de fácil reprodução; além disso, é uma espécie que se adapta facilmente ao cativeiro, alimenta-se de dietas inertes e de uma variedade de formulações de rações. Também produz uma grande quantidade de fezes em forma sólida e compacta, sendo uma espécie apropriada para estudos de nutrição em peixes.

A carnitina é derivada da lisina e é um composto muito higroscópico, facilmente solúvel em água, sendo requerida para o transporte de ácidos graxos de cadeia longa para dentro da mitocôndria, local onde ocorre o processo de betaoxidação. A necessidade de 1-carnitina pode exceder a capacidade de um indivíduo para sintetizá-la, tornando-se um nutriente condicionalmente essencial (Harpaz, 2005). A administração da carnitina pode melhorar o desempenho dos peixes devido ao aumento da eficiência da utilização da energia dos lipídios, possibilitando a economia da proteína e permitindo a incorporação desta proteína na produção de tecido muscular. A principal função celular da carnitina é o transporte de ácidos graxos ativos através da membrana mitocondrial interna (Bremer, 1962, citado por Harpaz, 2005).
Este papel da carnitina é fundamental para o crescimento da produção de peixes em cativeiro, uma vez que estes animais exigem um nível de proteína muito mais elevado em sua dieta quando comparados com outros animais de produção (Furuya et al., 2004; Bittencourt et al., 2010).

O custo da proteína é muito elevado. Além disso, parte da proteína nos peixes é desviada para ser usada como fonte de energia e não utilizada para o real crescimento da carcaça do animal (Wilson, 2002). A farinha de peixe é a principal fonte de proteína animal utilizada na fabricação de ração para peixes, porém, em função do seu preço de mercado muito elevado e do aspecto poluidor da água da proteína, durante as últimas duas décadas tem-se aumentado o interesse em se reduzir o seu nível nas rações.

Em muitos peixes carnívoros, que apresentam altos índices de exigência proteica, está sendo usada alimentação com alta energia, aumentando muito a porcentagem de gordura na dieta, alcançando valores acima de $35 \%$. Isto foi feito num esforço de reduzir o índice da farinha de peixes utilizado e conseguir a economia de proteína. A elevação da porcentagem de gordura na alimentação estimulou diversos estudos para melhorar a capacidade do peixe em utilizar eficientemente alimentações com altos níveis de energia (Harpaz, 2005). Desde que a carnitina foi associada com maior metabolismo de gordura, muitos estudos tentaram estabelecer correlações entre níveis mais elevados de carnitina nas dietas e o metabolismo de gordura com consequente redução dos níveis proteicos nas rações (Harpaz, 2005), pois a adição da carnitina à dieta dos peixes conduziria ao direcionamento da proteína à formação de tecidos, melhorando o crescimento dos animais, mesmo ao se usar dietas menos proteicas. $\mathrm{O}$ objetivo do experimento foi avaliar o efeito da inclusão da 1carnitina na dieta sobre o desempenho zootécnico do Trichogaster leeri.

\section{MATERIAL E MÉTODOS}

Foram elaboradas cinco dietas isocalóricas e isoproteicas com $28 \%$ de proteína bruta e $3100 \mathrm{kcal}$ de $\mathrm{ED} \mathrm{\textrm {kg } ^ { - 1 }}$ de dieta, em que se adicionou carnitina nas seguintes concentrações: $\mathrm{T} 1=0 \mathrm{mg}, \mathrm{T} 2=300 \mathrm{mg}, \mathrm{T} 3=600 \mathrm{mg}, \mathrm{T} 4=$ 900mg e T5 $=1200 \mathrm{mg}$, de l-carnitina $\mathrm{kg}^{-1}$ de ração. A carnitina foi dissolvida em álcool na 
concentração dos tratamentos, e, em seguida, cada solução foi borrifada sobre o respectivo lote de ração farelada, misturando-se de forma homogênea. As rações foram trituradas para que os animais pudessem ingerir a ração. Posteriormente, foram secas à sombra e sob ventilação, acondicionadas em embalagens plásticas e armazenadas sob refrigeração até o momento de sua utilização.

Foram utilizados $15 \mathrm{~T}$. leeri juvenis, com peso inicial de $0,5 \pm 0,2 \mathrm{~g}$, distribuídos aleatoriamente e individualmente em aquários circulares plásticos e transparentes de $2.000 \mathrm{~mL}$, com volume útil de $1.000 \mathrm{~mL}$ e renovação total da água a cada 48 horas. Os aquários menores ficavam em sistema de banho-maria em um recipiente maior, que continha água sob controle de temperatura, provido de aquecedor elétrico com termômetro. As rações diárias foram previamente pesadas e armazenadas em recipientes individuais e administradas três vezes ao dia, às nove, 13 e 17 horas, até a saciedade aparente, durante 45 dias, sob fotoperíodo de 10 horas de luz artificial fluorescente. A qualidade da água quanto à temperatura, $\mathrm{O} 2$ e $\mathrm{pH}$ foi monitorada com termômetro de máxima e mínima, oxímetro e pHmetro digitais, respectivamente.

Os animais foram pesados em balança digital $(0,01 \mathrm{~g})$ e medidos com ictiômetro $(0,01 \mathrm{~cm})$ no início e no final do experimento, aos 45 dias. As características avaliadas foram: comprimento total (CT), comprimento padrão $(\mathrm{CP})$, altura $(\mathrm{AL})$, peso inicial (PI), peso final (PF) e tamanho de cauda (TC), além do consumo de ração (CR) durante o período do experimento.

Os valores de peso e tamanho inicial e de peso e tamanho final foram utilizados na determinação do ganho de peso (GP) e do fator de condição (fC) (Vazzoler, 1996), sendo: $\mathrm{fC}=\left(\mathrm{wt} / \mathrm{ls}^{\mathrm{b}}\right) \times 100$, em que: $\mathrm{wt}=$ peso total, $\mathrm{lt}=$ comprimento total, $b=$ coeficiente angular da regressão da relação peso:comprimento.

A taxa de crescimento específico (TCE), expressa em \% ao dia, foi determinada pela expressão utilizada por Zuanon et al. (2004): $\mathrm{TCE}=(\mathrm{Wf}-\mathrm{Wi} / t) \times 100$, em que: $\mathrm{Wf}=$ peso final dos peixes em gramas; $\mathrm{Wi}=$ peso inicial dos peixes em gramas; $t=$ tempo em dias.

O efeito da inclusão de 1-carnitina sobre o peso total, comprimento total, ganho de peso e taxa de crescimento específico foi avaliado por meio de regressões polinomiais e correlações com auxílio do programa estatístico SAEG.

\section{RESULTADOS E DISCUSSÃO}

As médias e os desvios-padrão das variáveis relacionadas à qualidade de água, registrados durante o período experimental, foram: $28,0 \pm 0,5^{\circ} \mathrm{C}$ de temperatura; 6,0 0 0,4 de $\mathrm{pH}$; $5,5 \pm 1,0 \mathrm{mg} / \mathrm{L}$ de oxigênio dissolvido. Estes valores apresentaram-se dentro dos limites recomendados para peixes ornamentais e também para os da espécie utilizada (Zuanon et al., 2004).

Todas as características analisadas demonstraram que o tratamento de $900 \mathrm{mg}$ de carnitina $\mathrm{kg}^{-1}$ de ração foi o mais eficiente no desempenho zootécnico para o T. leeri (Tab. 1). Observaramse diferenças significativas $(\mathrm{P}<0,05)$ para $\mathrm{TC}$, $\mathrm{AL}, \mathrm{PF}$ e fC e, ainda, valores, com baixa significância estatística, para CT, com $\mathrm{P}<0,07$, e para GP e TCE, com $\mathrm{P}<0,06$, demonstrando efeito da carnitina sobre o desempenho dos animais. Todas as características analisadas comportaram-se de forma quadrática, em que: CT apresentou $\mathrm{R}^{2}=0,99(\mathrm{P}<0,07) ; \mathrm{TC}, \mathrm{R}^{2}=0,97$ $(\mathrm{P}<0,03) ; \mathrm{AL} \mathrm{R}^{2}=0,83(\mathrm{P}<0,03) ; \mathrm{PF}, \mathrm{R}^{2}=0,85$ $(\mathrm{P}<0,02)$; GP e TCE, $\mathrm{R}^{2}=0,94(\mathrm{P}<0,06)$ e $\mathrm{fC}$, $\mathrm{R}^{2}=0,87(\mathrm{P}<0,01)$. A influência do tratamento foi maior em PF, GP, TCE e fC.

Foram determinados os pontos máximos de melhor concentração de carnitina na dieta para cada variável, que apresentou significância. $\mathrm{GP}=0,3977$ - 0,0008285X - 0,000000413 X apresentou a concentração ideal de $1003,93 \mathrm{mg} / \mathrm{kg} ; \quad \mathrm{PF}=0,01045$ - 0,000863X $0,000000492 X^{2}$ a concentração ideal de $877,85 \mathrm{mg} / \mathrm{kg}$ de ração; TCE $=0,87828$ $0,001845 \mathrm{X}$ - 9,20635E-07 $\mathrm{X}^{2}$ a concentração ideal de $1002,04 \mathrm{mg} / \mathrm{kg}$; e $\mathrm{fC}=0,844286$ $0,000471 \mathrm{X}-2,53968 \mathrm{E}-07 \mathrm{X}^{2}$ a concentração ideal de $921,99 \mathrm{mg} / \mathrm{kg}$ (Fig. 1). 
Níveis de carnitina...

Tabela 1. Valores médios de características de desempenho corporal de Trichogaster leeri suplementados com l-carnitina na dieta

\begin{tabular}{l|llllllll}
$\begin{array}{l}\text { 1-carnitina } \\
(\mathrm{mg} / \mathrm{kg})\end{array}$ & $\mathrm{CT}$ & $\mathrm{CP}$ & $\mathrm{TC}$ & $\mathrm{AL}$ & $\mathrm{PF}$ & $\mathrm{GP}$ & $\mathrm{TCE}$ & $\mathrm{fC}$ \\
\hline 0 & 4,47 & 3,61 & 0,85 & 1,22 & 1,07 & 0,42 & 0,93 & 0,86 \\
300 & 4,79 & 3,73 & 1,06 & 1,38 & 1,23 & 0,57 & 1,26 & 0,94 \\
600 & 4,89 & 3,72 & 1,16 & 1,42 & 1,33 & 0,73 & 1,61 & 1,01 \\
900 & 4,88 & 3,79 & 1,09 & 1,52 & 1,53 & 0,87 & 1,94 & 1,12 \\
1.200 & 4,70 & 3,71 & 0,99 & 1,30 & 1,33 & 0,77 & 1,70 & 1,02 \\
\hline
\end{tabular}

$\mathrm{CT}=$ comprimento total, $\mathrm{CP}=$ comprimento padrão, $\mathrm{TC}=$ tamanho de cauda, $\mathrm{AL}=$ altura, $\mathrm{PF}=$ peso final, $\mathrm{GP}=$ ganho de peso, $\mathrm{TCE}=$ taxa de crescimento específico, $\mathrm{fC}=$ fator de condição corporal.

Ao se calcularem os pontos máximos de influência da suplementação de 1-carnitina na dieta para T.leeri, os valores sugeridos ficam entre 900 e $1.000 \mathrm{mg} / \mathrm{kg}$ de ração, entretanto as variáveis mais importantes no cultivo dessa espécie ornamental são o GP e a TCE, que estão intimamente ligados à redução do tempo de criação dos indivíduos, colocando-os no mercado em menor tempo. As diferenças de GP entre as concentrações de 1-carnitina testadas podem ser observadas na Fig.1a, e de TCE, na Fig.1c. Além disso, os valores das variáveis PF e fC (Fig. 1b e 1d) podem ser limitados por características anatômicas de cada espécie e mascarar os resultados quando avaliados isoladamente, sendo mais apropriada sua utilização em conjunto com valores de GP e TCE. Sendo assim, os valores sugeridos neste estudo, para a suplementação de 1-carnitina para $T$. leeri, seriam de cerca de $1.000 \mathrm{mg} / \mathrm{kg}$ de ração.

Segundo a matriz de correlação de Pearson, houve correlação positiva entre quantidade de inclusão de carnitina com PF $(0,658)$, GP $(0,763)$, TCE $(0,762)$ e FC $(0,767)$, indicando que a espécie estudada reagiu de forma positiva à administração de carnitina, o que refletiu na melhoria dos índices zootécnicos, com a suplementação de carnitina.

O GP é de grande importância para a produção de peixes e talvez seja o fator de maior interesse quanto à suplementação da dieta com a carnitina. O maior crescimento que a suplementação da carnitina pode promover é atribuído ao aumento na utilização da energia, em consequência do aumento da queima de gorduras. Isso já foi descrito em robalo europeu (Dicentrarchus labrax), bagre africano (Clarias gariepinus), tilápias híbridas (Oreochromis niloticus $x O$. aureus), carpa comum (Cyprinus carpio) e em diversas outras espécies (Santulli et al., 1988;
Keshavanath e Renuka, 1998; Harpaz, 2005). Também há relatos da promoção do crescimento (embora não significativa) para carpa comum em estudos com diferentes lotes de animais (Harpaz, 2005). Entretanto, suplementação de carnitina que não resultou em nenhum efeito sobre o crescimento ocorreu em espécies como truta (Oncorhynchus mykiss), bagre africano, ciclídeos ornamentais e em guppy (Poecilia reticulata), indicando que há diferentes respostas à suplementação de 1-carnitina (Rodehutscord, 1995; Schreiber et al., 1997). Gonçalves et al. (2010), entretanto, descreveram que pode haver redução na excreção de amônia nas fezes com a suplementação de carnitina na dieta, mesmo sem apresentar melhora direta no desempenho zootécnico dos animais, podendo influenciar no crescimento deles. Essas diferenças de reação nas quantidades testadas nos experimentos citados mostram que há não somente diferença entre as espécies, mas também de um animal para outro dentro de diferentes grupos.

Diferenças entre os resultados encontrados nesta pesquisa com os de outros estudos também podem ser atribuídas às variações na composição química da carnitina. Santulli e D'Amelio (1986a,b) estudaram os efeitos da suplementação de carnitina na dieta de robalo europeu utilizando dietas com 250mg de 1-carnitina ou d-carnitina $/ \mathrm{kg}$. Os resultados demonstraram que o uso de d-carnitina resultou em uma taxa de crescimento significativamente menor que a do grupo-controle, sem carnitina. Por outro lado, os peixes alimentados com 1-carnitina (sob as mesmas condições experimentais) apresentaram melhor crescimento que os do grupo-controle (Harpaz, 2005). Mesmo podendo haver diferenças entre as formas da carnitina, a maioria dos estudos relata apenas o uso de carnitina, sem especificação, o que dificulta ainda mais as comparações. 


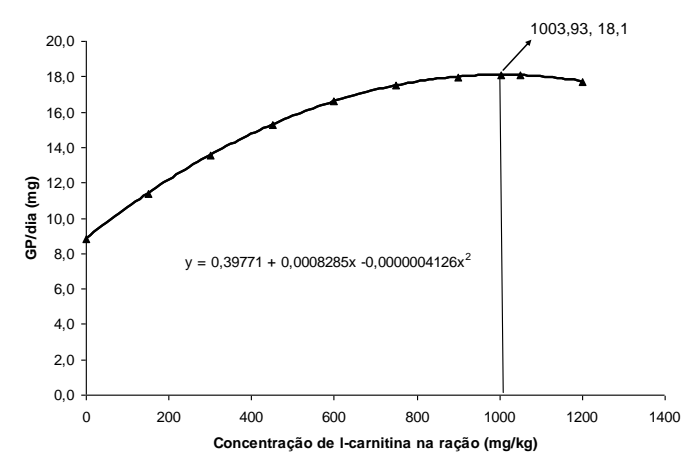

A

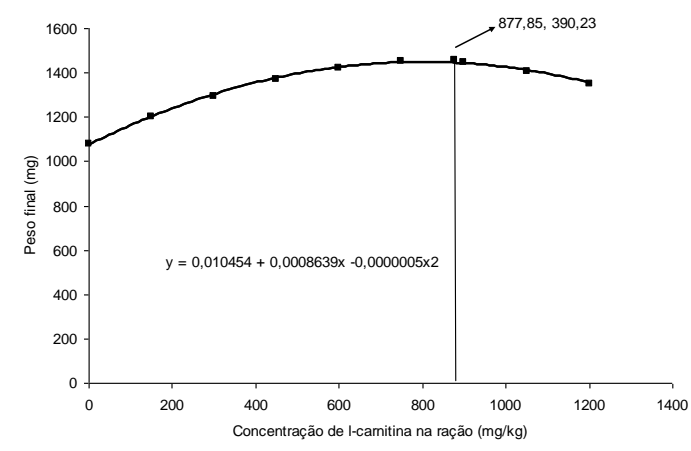

B

Figura 1. Ponto máximo de concentração de 1-carnitina em mg/kg, para ganho de peso (a), peso final (b), Taxa de crescimento específico (TCE) (c) e fator de condição (d), para Trichogester leeri.

Assim como no atual trabalho, Twibell e Brown (2000) também observaram significativo aumento no consumo de ração em híbridos de perca (Morone saxatilis $\mathrm{x} M$. chrysops) alimentados com carnitina $370 \mathrm{mg} / \mathrm{kg}$ de ração em comparação com os do grupo-controle, sem carnitina, mesmo com valores discretos do desempenho zootécnico. A 1-carnitina está envolvida na rápida disposição de energia para reparação e manutenção da integridade das membranas, além de ser amplamente útil durante a divisão celular; dessa forma, animais em fase de crescimento poderiam ser mais eficientes na utilização da carnitina presente na ração, explicando diferentes respostas à suplementação de carnitina em diferentes fases da vida do animal.

O custo-benefício é outra questão importante a ser considerada quanto à inclusão da carnitina na alimentação de algumas espécies de peixes. Mesmo que a 1-carnitina tenha efeito positivo, a quantidade exigida dessa substância, de custo elevado, pode não justificar o crescimento

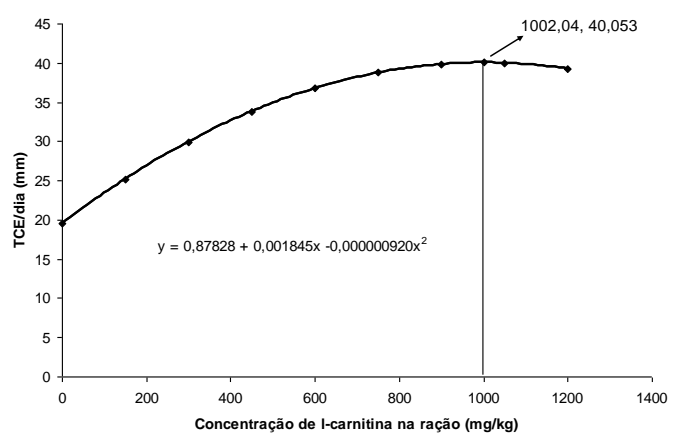

C

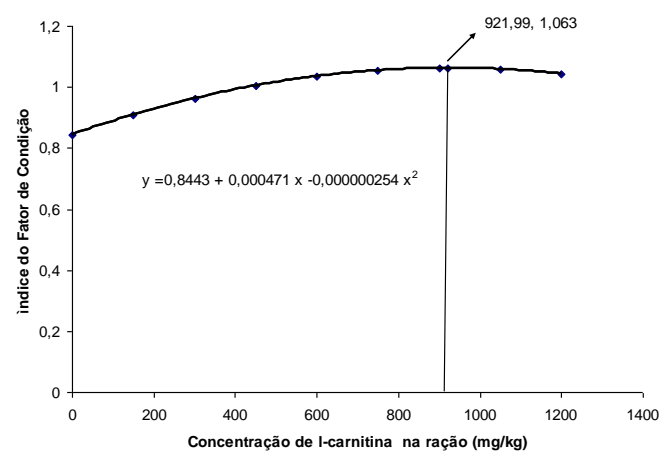

D

adicional obtido. Becker et al. (1999) abordaram esse aspecto ao afirmarem que o melhor crescimento obtido pela adição de $150 \mathrm{mg} / \mathrm{kg}$ carnitina na dieta de tilápia híbrida (O. niloticus $x$ O. aureus) foi igual ao resultado obtido com melhor conversão alimentar, pois ocorreu redução de apenas $13 \%$ do alimento administrado, mantendo o mesmo peso final, não apresentando vantagens econômicas para o seu uso.

A maioria dos estudos que apresentam efeitos positivos da suplementação de l-carnitina na alimentação de peixes mostrou que, na suplementação, são necessárias quantidades acima de $150 \mathrm{mg} / \mathrm{kg}$, podendo chegar até $1.000 \mathrm{mg} / \mathrm{kg}$ em algumas espécies, o que pode tornar esse procedimento economicamente inviável ou discutível. Os aspectos ecológicos de uma melhor conversão alimentar também devem ser considerados, além de apenas se conseguir melhor aproveitamento da gordura dos alimentos. Sendo assim, é evidente a carência de mais estudos, tanto sobre a contribuição da 
carnitina para a melhora no desempenho corporal de peixes, como sobre seu real papel na fisiologia das diferentes espécies.

\section{CONCLUSÕES}

A inclusão de 1-carnitina em até $1.000 \mathrm{mg} / \mathrm{kg}$ de ração, aproximadamente, exerceu efeito positivo sobre ganho de peso, peso final, taxa de crescimento específico e fator de condição para juvenis de T. leeri. Níveis de 1-carnitina entre 877 e $1.004 \mathrm{mg} / \mathrm{kg}$ de ração são valores mais indicados para o melhor crescimento desta espécie.

\section{REFERÊNCIAS BIBLIOGRÁFICAS}

BECKER, K.; SCHREIBER, S.; ANGONI, C. et al. Growth performance and feed utilization response of Oreochromis niloticus $x$ Oreochromis aureus hybrids to 1-carnitine measured over a full fattening cycle under commercial conditions. Aquaculture, v. 174, p.313-322, 1999.

BITTENCOURT, F.; FEIDEN, A.; SIGNOR, A.A. et al. Proteína e energia em rações para alevinos de piavuçu. Rev. Bras. Zootec., v.39, p.2553-2559, 2010.

COLE, B.; TAMARU, C.S.; BAILEY, R. et al. A manual for commercial production of the gourami, Trichogaster trichopterus, a temporary paired spawner. Cent. Trop. Subtrop. Aquac., v.135, p.37, 1999.

DEGANI, G. The effect of temperature, light, fish size and container size on breeding of Trichogaster trichopterus (B\&S 1801). Aquac. Engen., v.9, p.367-375, 1990.

DIAGNÓSTICO geral das práticas de controle ligadas a exploração, captura, comercialização, exportação e uso de peixes para fins ornamentais e de aquariofilia. Brasília: Instituto Brasileiro do Meio Ambiente e dos Recursos Naturais Renováveis, 2008. 217p.

FURUYA, W.M.; PEZZATO, L.E.; BARROS, M.M. Use of ideal protein concept for precision formulation of amino acid levels in diets with and without dicalcium phosphate for juvenile Nile tilapia (Oreochromis niloticus) Aquac. Res., v.35, p.1110-1116, 2004.
GONÇALVES, J. F. M.; TURINI, B. G. S.; OZÓRIO, R.O.A. Performance of juvenile turbot (Scophthalmus maximus) fed varying dietary Lcarnitine levels at different stocking densities. Sci. Agric., v.67, p.151-157, 2010.

HARPAZ, S. 1-Carnitine and its attributed functions in fish culture and nutrition - a review. Aquaculture, v.249, p.3-21, 2005.

KESHAVANATH, P.; RENUKA, P. Effect of dietary 1-carnitine on growth and body composition of fingerling rohu, Labeo rohita (Hamilton). Aquac. Nut., v.4, p.83-87, 1998.

LIVENGOOD, E.J.; CHAPMAN, F.A. The ornamental fish trade: An introduction with perspectives for responsible aquarium fish ownership. Gainesville: Institute of Food and Agricultural Sciences, 2007. p.1-8.

RODEHUTSCORD, M. Effects of supplemental dietary 1-carnitine on the growth and body composition of rainbow trout Oncorhynchus mykiss fed high-fat diets. J. Anim. Physiol.: Anim. Nutr., v.73, p.276-279, 1995.

SANTULLI, A.; D'AMELIO, V. Effects of supplemental dietary carnitine on growth and lipid metabolism of hatchery-reared sea bass Dicentrarchus labrax L. Aquaculture, v. 59, p.177-186, 1986a.

SANTULLI, A.; D'AMELIO, V. The effects of carnitine on the growth of sea bass, Dicentrarchus labrax L., fry. J. Fish Biol., v.28, p.81-86, 1986b.

SANTUlli, A.; MODICA, A.; CURATOLO, A. et al. Carnitine administration to sea bass Diacentrarchus labrax L. during feeding on a fat diet: modification of plasma lipid levels and lipoprotein pattern. Aquaculture, v.68, p.345$351,1988$.

SCHREIBER, S.; BECKER, K.; BRESLER, V. et al. Dietary 1-carnitine protects the gills and skin of guppies (Poecilia reticulata) against anionic xenobiotics. Comp. Biochem. Physiol., v.117, p.99-102, 1997.

TWIBELL, R.G.; BROWN, P.B. Effects of dietary carnitine on growth rates and body composition of hybrid striped bass Morone saxatilis male $\mathrm{x} M$. chrysops female. Aquaculture, v.187, p.153-161, 2000. 
VAZZOLER, A.E.A.M. Biologia da reprodução de peixes teleósteos: teoria e prática. Maringá: EDUEM, SBI, 1996. 169p.

WILSON, R.P. Amino acids and proteins. In: HALVER, J.E.; HARDY, R.W. (Eds.). Fish nutrition. 3ed. San Diego, CA: Academic, 2002. p.143-179.
ZUANON, J.A.S.; ASSANO, M.; FERNANDES, J.B.K. Desempenho de tricogaster (Trichogaster trichopterus) submetido a diferentes níveis de arraçoamento e densidades de estocagem. Rev. Bras. Zootec., v.33, p.1639-1645, 2004. 